\title{
Five Hums of a Hospital
}

\section{RAAMESH GOWRI RAGHAVAN}

\section{Hum \#01}

koel calls

the ambulance's

contralto

It was only in the afternoon that I saw Dad for the last time. Haggard, oxygen at 70, being changed into a hospital gown. My pulse shot to 133 (I had an oximeter on hand) wondering whether this was the last meeting. There had been too many pictures of anonymous people in PPE cremating body bags.

In the evening, I was myself bundled into a Maruti van. In all its lightness of being, it was tossed about on the pitching seas that pass for our roads. With a fever touching 103, I signed the hospital's indemnity for my own death. Wheeled into the white walls, it was my turn to imagine myself in a body bag.

waiting

for her ambulance

mother

waters the house plants

to last her absence

\section{Hum \# 1}

The ward and its white walls have two lives. By day, there are comers and goers and small talk between the medical staff and us three patients. By night, it is the Morse code between the lights through the chequered stained glass and the shadows on the walls. The fan's hum finds a crazy but delicate interaction with that of the A/C. An occasional koel chirp suggests an outside world.

Author: Raamesh Gowri Raghavan (iambecomedeath@gmail.com) Editor, Narrow Road Literary Journal and Director, loncure Tech Pvt Ltd, Vijay Enclave, Waghbil Naka, Thane 400615 INDIA.

To cite: Raghavan RG. Five Hums of a Hospital. Indian J Med Ethics. Published online on November 19, 2021 DOI:10.20529/IJME.2021.089.

Manuscript Editor: Rakhi Ghoshal

(c) Indian Journal of Medical Ethics 2021 solitaire

cough syrups trade places

with old vials

\section{Hum \#2}

the way they wipe the doorknob after me

Time hangs heavy on my hands, but perhaps not as much as the contraption they've stuck to it for the IV fluid. The drip provides a hum of its own - my eye stays glued fascinated to it. Any arrhythmia reflects in the pulse. From the plastic saline bag-bottle to the stop cock and then down the tube. I watch till it drips dry, or I must summon the nurse to give me a pee break.

\section{\#Hum 3}

It hangs pendulously from the saline hook, having injected its seed into me. Flailing in the eddy of the fan, it glints in the light of the lobby. A sole mosquito perches on it, as some kind of omen, or perhaps as a bested rival. The will-it-won't-it of the hanging drop keeps me mesmerised. The hum leaves me to my thoughts, pushed by a steady mental om mane padme hum into nothingness, a slow slip into the nada of the cosmos.

convalescence

buried in the thrill of

Indrajaal comics

\section{\#Hum 4}

They wheeled in mother from the ICU today into the ward I am in. That set up new hums as the lady is very popular with the staff, who compete to feed her and chat with her.

Those old friendships with empty, rolling vials of itolizumab and remdesivir and dexamethasone and pantoprazole might be ending, though I never got around to asking what they did for a living. I never missed the bag of plasma though thankful for the anonymous donor and to be paid forward but that jaundiced yellow bag hanging from its gibbet was not a soothing sight.

WhatsApp chatter

they tire of politics to talk

of train models 


\section{\#Hum 5}

discharge day

this unkept promise

of mangoes

The last word I probably want to hear is augmentin. I don't know whether it was a friend or fiend. It had that jaundiced yellow that dripped into my veins, jaundicing my worldview too. Although that was simply a white ceiling with paint spots.

The hum is different as the discharge-word is bandied about. The trainees and young paramedics milling about in the ward, in their flimsy PPEs, flirting with mother and taking selfies. And mother's cheerful banter.

empty nest -

looking forward to

dettol and hot water

${ }^{1}$ Note: A haibun is a prose poem that combines a very short essay with one or more haiku. The essay is made of a few sentences which recollect an experience one has had in life. It is almost always written in the first person.

A haiku is a poem in three lines, usually less than seventeen syllables long. It speaks of nature, especially one's personal experience. It may also speak of human nature and human foibles in an ironic or satirical way. 